\title{
Detections and simulations of tropospheric water vapor fluctuations due to trapped lee waves by ALOS-2/PALSAR-2 ScanSAR interferometry
}

\author{
Youhei Kinoshita ${ }^{*}$, Yu Morishita ${ }^{2}$ and Yukiko Hirabayashi ${ }^{3}$
}

\begin{abstract}
Detailed wave-like spatial patterns of atmospheric propagation delay signals associated with mountain lee waves were detected in Hokkaido and Tohoku by synthetic aperture radar (SAR) interferometry (InSAR) with the ScanSAR mode observation data of a Phased Array-type L-band Synthetic Aperture Radar 2 on board the Advanced Land Observing Satellite 2. Both cases occurred under stable atmosphere conditions. The InSAR-observed peak-to-trough line of sight changes in the mountain wave signals was 4 and $5 \mathrm{~cm}$ with the horizontal wavelengths of 9 and $15 \mathrm{~km}$ in Hokkaido and Tohoku, respectively. Locations of positive phase maxima in the mountain wave signals coincides with locations of cloud streets observed by visible satellite imagery, indicating that crests of mountain waves contain relatively much water vapor compared with wave troughs. Numerical weather simulations with the horizontal grid spacing of $1 \mathrm{~km}$ were performed to reproduce InSAR phase variations, and as a result those simulations could reasonably reproduce observed wave amplitudes and wavelengths in both cases. On the other hand, numerical simulations tended to overestimate wave attenuation rates: simulated mountain waves decreased as the wave propagated faster than those of observed signals. Because the simulated wave attenuation rate is sensitive to physics in the planetary boundary layer (PBL), we investigated the reproducibility of five PBL schemes implemented in the WRF model. As a result, all the PBL schemes showed little attenuation except for the Yonsei University scheme (YSU), while the wavelength in the YSU was most close to the observation. Our study demonstrated the uniqueness and usefulness of InSAR for meteorological application as the ability to map the detailed water vapor distribution regardless of cloud cover. In addition, the reasonable reproducibility of the water vapor delay signal due to lee waves by the numerical weather model encourages researchers who tackle the correction of the tropospheric propagation delay, increasing the accuracy in detecting surface deformations.
\end{abstract}

Keywords: ALOS-2/PALSAR-2, Synthetic aperture radar (SAR), InSAR, ScanSAR interferometry, Mountain wave, Propagation delay, Water vapor, Numerical weather simulation

\section{Introduction}

The trapped lee wave is one of the mountain wave modes, which propagates horizontally downstream of the crest of the mountain under stably stratified condition (Durran

\footnotetext{
*Correspondence: kinoshita_youhei@restec.or.jp

${ }^{1}$ Research and Development Department, Remote Sensing Technology Center of Japan, 3-17-1, Tokyu REIT Toranomon Building, 3F, Minato-ku, Tokyo, Japan

Full list of author information is available at the end of the article
}

1990). Trapped lee waves often involve cloud streets at vertically displaced regions when the air is nearly saturated, and hence, they are visualized by satellite imagery. However, lee waves under a dry condition are invisible and sometimes cause serious aviation accidents due to the abrupt change in vertical winds (Uhlenbrock et al. 2007). The horizontally propagating trapped lee wave is a resonant wave whose energy is contained within a lower tropospheric resonant wave duct (Hills et al. 2016). Theoretical studies revealed that the attenuation of trapped 
waves depends on several factors such as the surface roughness, the heat flux of the surface and the energy leakage through the upper stratosphere (Jiang et al. 2006; Durran et al. 2015). Muñoz-Esparza et al. (2016) performed non-hydrostatic numerical weather simulations with four different planetary boundary layer (PBL) schemes to investigate the reproducibility of PBLs for mountain wave flows. But observational validations of the horizontal wave attenuation were relatively less compared to theoretical studies because both ground-based wind observation and satellite imagery have the difficulty in capturing whole structure of lee waves. Therefore, observations of the spatial structure of the trapped lee wave are of importance for both aviation disaster mitigation and mechanism investigation.

Observations of mountain waves have been reported by numerous studies. Ralph et al. (1997) detected two cases of vertical wind fluctuations and parallel cloud streets associated with trapped lee waves downstream of the Colorado Rocky Mountains near Boulder by a radar wind profiler and satellite imagery. Lane et al. (2000) investigated a mountain wave mechanism by the use of a numerical modeling and intense observation campaign of the New Zealand Southern Alps Experiment. Satellite visible imagery has been widely used for understanding spatial extents of clouds associated with mountain waves (e.g., Worthington 2001; Feltz et al. 2009). Recently, spatial observations of vertically integrated precipitable water vapor (PWV) have been achieved by high-resolution multispectrum imagery such as the Moderate Resolution Imaging Spectroradiometer (MODIS) on board the National Aeronautics and Space Administration's Terra/ Aqua satellite and the Medium Resolution Imaging Spectrometer (MERIS) on board the European Space Agency (ESA)'s Envisat satellite ( $\mathrm{Li}$ et al. 2012; Chang et al. 2014). These meteorological observations have attributed to the understanding of the mountain wave mechanism, but each observation technique has some of its intrinsic disadvantages, for example, PWV observations by MODIS and MERIS are limited in the cloud-free condition and a horizontal resolution is approximately $1 \mathrm{~km}$ at best, which is insignificant for resolving detailed structure of lee waves (less than an order of kilometer).

Synthetic aperture radar interferometry (InSAR) is a satellite geodetic technique to map surface deformation with an unprecedented spatial resolution of a few meters and a precision comparable to global navigation satellite system (GNSS) observations (Rosen et al. 2000). InSAR can be generated by subtracting two single look complex images (SLCs) acquired at nearly the same satellite position but at a different time, and its phase signal contains not only surface deformation, but also atmospheric contributions due to the ionosphere and water vapor in the troposphere as well as GNSS observations. Advantages of InSAR for the meteorological application are that (1) InSAR has an ability to observe the spatial water vapor distribution with an unprecedented spatial resolution when there are no other contributions in the image such as surface displacements and ionospheric phase disturbances (e.g., Mateus et al. 2017); (2) InSAR requires no observation instruments on the ground; and (3) InSAR microwave penetrates clouds and volcanic plumes that consist of relatively small particles compared to the microwave wavelength. The phase modification due to atmospheric phenomena has been regarded as a "noise" for higher-precision InSAR observation for geophysical research such as earthquake and volcanic activity. To cope with this, many researches have been conducted to separate the atmospheric effect from deformation signals by the use of time series methods such as the persistent scatterer interferometry (PSInSAR; Ferretti et al. 2000) and the Small BAseline Subset interferometry (SBAS; Berardino et al. 2002), external observation data such as GNSS propagation delay data and spatial PWV data derived from multispectrum satellite images (e.g., Onn and Zebker 2006; Li et al. 2009) and numerical modeling through the use of meteorological reanalysis data and numerical weather model outputs (e.g., Foster et al. 2006; Jolivet et al. 2011; Mateus et al. 2013b).

On the contrary, Hanssen et al. (1999) regarded the atmospheric delay signal as a meteorological signal and confirmed that its spatial distribution derived by an ESA's European Remote Sensing Satellite tandem observation corresponded very much to that by a simultaneously derived weather radar images around the Netherlands. Following Hanssen's work, Kinoshita et al. (2013) detected water vapor distribution during a heavy rain event in central Japan using a Phased Array-type L-band Synthetic Aperture Radar (PALSAR), an L-band synthetic aperture radar (SAR) sensor on board the Advanced Land Observing Satellite (ALOS) launched by the Japan Aerospace Exploration Agency (JAXA). They found that a convective system contained anomalously much amount of water vapor that reached up to $13 \mathrm{~mm}$ in PWV higher than that of the surrounding average. In addition, Pichelli et al. (2015) conducted a three-dimensional data assimilation (3DVAR) experiment by merging a InSAR-derived water vapor field into the revised Pennsylvania State University/National Center for Atmospheric Research mesoscale model (MM5) with a horizontal resolution of $1 \mathrm{~km}$ at Rome (Central Italy). Their simulation assimilating InSAR water vapor information resulted in statistically positive effects on the precipitation forecast. Mateus 
et al. (2016) also conducted a 3DVAR experiment using the Weather and Research Forecasting (WRF) model and the WRF model data assimilation system and showed a correction of PWV bias and an improvement of a weak to moderate precipitation prediction. Benevides et al. (2016) estimated a three-dimensional water vapor field by combining GNSS slant delay data and an InSAR-derived water vapor distribution with the tomographic method. Although there are some difficulties to extract water vapor information from the InSAR phase, the uniqueness and effectiveness of InSAR water vapor information for meteorology have been investigated by several studies (e.g., Hanssen et al. 2001; Kinoshita et al. 2013; Alshawaf et al. 2014).

This study demonstrates a uniqueness of the spatial water vapor observation by InSAR for mountain wave studies and performs mesoscale numerical weather simulations to reproduce observed mountain wave signals derived by InSAR observations. Mountain wave events we demonstrated occurred on September 6, 2014, in Hokkaido and on April 30, 2016, in Tohoku region (Fig. 1). We also investigated an impact of using different PBL schemes for mountain wave simulations. This paper is organized as follows. The next section describes the principle of the microwave propagation delay, InSAR data processing and a numerical weather simulation setting. Results, discussions and the conclusion are described following the data and methods section. In the results section, we at first examined synoptic conditions by analyzing radiosonde observation data and objective analysis data around Japan, clarifying whether atmospheric conditions were preferred to generate mountain waves or not. Then, we showed derived InSAR images that detected line-shaped signals associated with mountain waves. Finally, numerical simulation results were shown in the last part of the result section.

\section{Data and methods}

\section{Propagation delay theory and modeling}

The propagation delay on microwave is well-known effect in space geodetic tools like GNSS, very long baseline interferometry and InSAR. When a microwave transmitted from radar passes through the Earth's atmosphere, its velocity and direction are modified due to the different refractive index from the vacuum. In terms of the propagation delay, the refractivity $N$ is often used instead of the refractive index $n$ because the variation of $n$ has an order of less than $10^{-4}$. The refractivity in the neutral atmosphere is expressed as (Thayer 1974),

$$
N=10^{6}(n-1)=k_{1} \frac{P_{\mathrm{d}}}{T}+k_{2} \frac{P_{\mathrm{v}}}{T}+k_{3} \frac{P_{\mathrm{v}}}{T^{2}}+N_{l}
$$

where $N$ represents the refractivity, $P_{\mathrm{d}}$ and $P_{\mathrm{v}}$ represent partial pressure of dry air and water vapor $(\mathrm{hPa}), T$ represents absolute temperature $(\mathrm{K}), N_{l}$ represents a contribution of hydrometeors and $k_{1}, k_{2}$, $k_{3}$ are experimentally determined constants of $k_{1}=77.604 \pm 0.014(\mathrm{~K} / \mathrm{hPa}), \quad k_{2}=64.79 \pm 0.08(\mathrm{~K} / \mathrm{hPa})$, $k_{3}=(3.776 \pm 0.004) \times 10^{5}\left(\mathrm{~K}^{2} / \mathrm{hPa}\right)$ (Bevis et al. 1992). $N_{l}$ can be significant only in a case of well-developed convective systems (Kinoshita et al. 2013). Therefore, we ignore the hydrometeor's contribution afterward. In Eq. (1), temperature and pressure impacts to the InSAR propagation delay are negligible in most cases (Kinoshita and Furuya 2017). An amount of the propagation delay is obtained by integrating Eq. (1) along the microwave path,

$$
L_{\mathrm{e}}=\int_{\mathrm{atm}}(n(r)-1) d \mathrm{~s}+\left(\int_{\mathrm{atm}} d \mathrm{~s}-\int_{\mathrm{vac}} d \mathrm{~s}\right),
$$

where $r$ indicates a position from the earth center. In Eq. (2), the first term in the right-hand side represents the electromagnetic delay due to the change in the phase

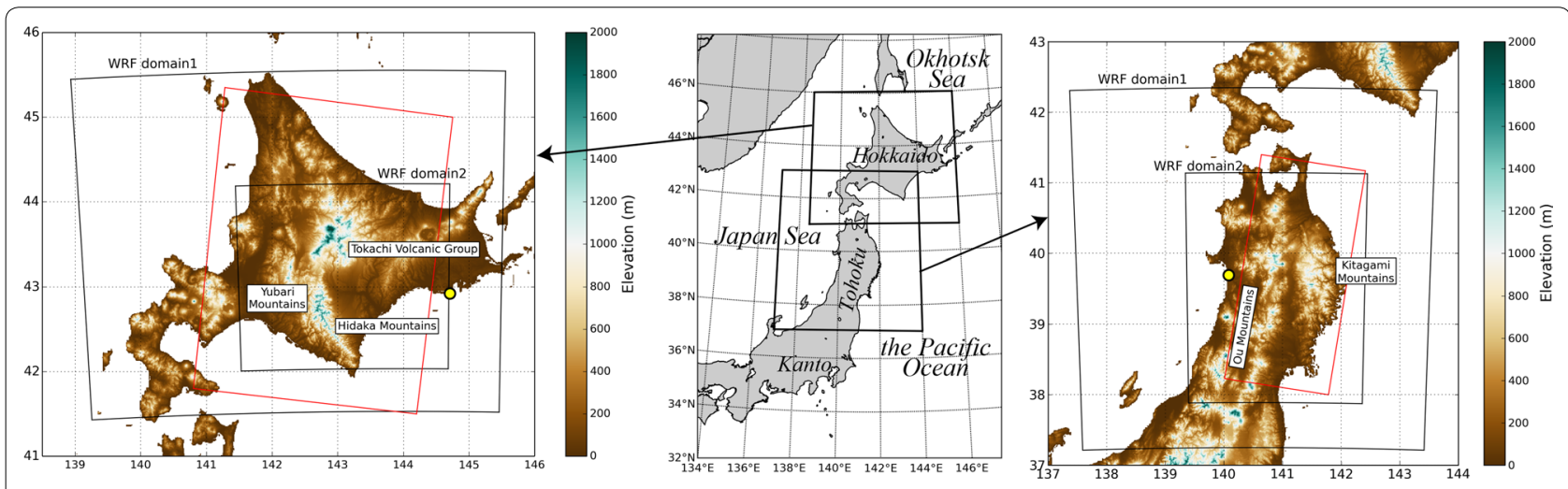

Fig. 1 Regions of interest Thin black boxes in left and right figures indicate domains of WRF simulations and red boxes indicate SAR observation areas 
velocity and the second term represents the ray bending effect (Hobiger et al. 2008).

In this study, we used a ray tracing method to calculate the propagation delay amount in the troposphere based on the three-dimensional distribution of meteorological variables by the method of Hobiger et al. (2008). The ray tracing method explicitly calculates effects of both bending and velocity change and thus enables us to calculate the propagation delay amount accurately. The ray tracing method requires three-dimensional atmospheric variables of pressure, temperature and water vapor. As the input of the ray tracing method, we use outputs of numerical weather simulations described in the following section.

\section{InSAR analysis}

The InSAR phase signal includes various contributions and can be expressed as,

$$
\phi=\phi_{\text {orb }}+\phi_{\text {topo }}+\phi_{\text {def }}+\phi_{\text {iono }}+\phi_{\mathrm{NA}}+\phi_{\text {noise }} \text {. }
$$

In Eq. (3), $\phi_{\text {orb }}$ represents the orbital fringe, $\phi_{\text {topo }}$ represents the topographic effect, $\phi_{\text {def }}$ represents surface deformation occurred between two acquisitions, $\phi_{\text {iono }}$ represents the phase advance effect of the ionospheric disturbance, $\phi_{\mathrm{NA}}$ represents the propagation delay effect in the neutral atmosphere and $\phi_{\text {noise }}$ represents other noises such as decorrelation due to longer time interval or a change in surface scattering property. The ionospheric contribution is dispersive, which is significant for the L-band SAR (e.g., Gray et al. 2000). Empirically the spatial wavelength of the ionospheric effect in InSAR is several tens of kilometers (e.g., Meyer 2011). Therefore, we can remove its effect by long-wavelength fitting procedure described below. The neutral atmospheric effect in InSAR is a difference of two acquisition time $\phi_{\mathrm{NA}}=\phi_{\mathrm{NA}}^{\text {slave }}-\phi_{\mathrm{NA}}^{\text {master }}$, and $\phi_{\mathrm{NA}}$ primarily reflects water vapor heterogeneity in the troposphere because the effect of dry air is spatially homogeneous in a typical InSAR observation range (Zebker et al. 1997).

We used ALOS-2/PALSAR-2 SLCs acquired on the ScanSAR mode to generate interferograms. In contrast to the ordinary strip-map mode that has a swath of approximately $70 \mathrm{~km}$, the ScanSAR mode improves observation swath approximately 5 times $(350 \mathrm{~km})$ by scarifying the spatial resolution in the along-track (azimuth) direction and the signal-to-noise ratio. Original spatial resolutions of ALOS-2/PALSAR-2 ScanSAR mode are 19 and $26 \mathrm{~m}$ in range (along line of sight direction) and azimuth direction, respectively. The Radar Interferometry Calculation Tools (RINC; Ozawa et al. 2016) version 0.37 was used for the interferometric processing. Topographic and orbital fringes were modeled and removed by the use of the 10-meter ellipsoidal height data by the Geospatial
Information Authority of Japan and the precise orbit information. To enhance the coherence that is an indicator of interference quality, each interferogram was multilooked before the unwrapping to be a horizontal resolution of approximately $300 \mathrm{~m}$. For the unwrapping procedure, the Statistical-Cost, Network-Flow Algorithm for Phase Unwrapping (SNAPHU) package (Chen and Zebker 2002) with the minimum spanning tree method was used. Because residual long-wavelength fringes were significant in derived interferograms, we removed them by fitting quadratic plane to each interferogram.

\section{Numerical weather modeling}

The WRF model is a non-hydrostatic numerical weather model (Skamarock et al. 2008). We used the WRF-ARW version 3.7.0 in the study. We set two domains that have horizontal resolutions of $3 \mathrm{~km}$ for the outer domain and $1 \mathrm{~km}$ for the inner domain, respectively. These domains are one-way nested, indicating that boundary conditions for the finer domain are updated by coarser domain outputs. Since trapped lee waves typically have wavelengths of around $15.8 \pm 4.5 \mathrm{~km}$ (Ralph et al. 1997), the spatial resolution of the inner domain is enough to explicitly resolve mountain wave phenomena. The horizontal grid numbers for the finer domains are $262 \times 244$ at the case of Hokkaido and $245 \times 360$ at the case of Tohoku in north-south and east-west directions, respectively. The maximum height was set to $100 \mathrm{hPa}$ (approximately $15,000 \mathrm{~m}$ a.s.l.) and the number of vertical layers is 50 , which is stretched to be a finer resolution in the lower atmosphere. We do not use cloud parameterization schemes for all simulations. We use the Yonsei University scheme (YSU), which is the WRF default setting and appropriate for the mesoscale modeling, for the boundary layer scheme and the MM5 scheme for the surface layer physics scheme (Hong et al. 2006). The WRF singlemoment three-class microphysics scheme that includes the prognostic water substance variables of water vapor, cloud water/ice, and rain/snow was used for the microphysics. As an initial and boundary condition, we used the MesoScale Model (MSM) objective analysis data provided by the Japan Meteorological Agency whose spatial resolution is $5 \mathrm{~km}$ at surface and $10 \mathrm{~km}$ above surface, high-resolution sea surface temperature (SST) data from the National Centers for Environmental Prediction (NCEP) and NCEP final reanalysis data for soil parameters. MSM data are an operational objective analysis that has a temporal resolution of $3 \mathrm{~h}$ covering the whole area of Japan. The 30-arcsecond GTOPO30 (approximately $1 \mathrm{~km}$ at the equator) was used for the topography. We set simulation domains covering whole areas where mountain waves excited (see Fig. 1). The simulation periods were from 18:00 UTC on September 5, 2014, to 06:00 
UTC on September 6, 2014, for the case of Hokkaido and from 18:00 UTC on April 29, 2016, to 06:00 UTC on April 30,2015 , for the case of Tohoku, respectively. Simulated WRF outputs were then converted to propagation delay with the ray tracing method described in subsection 2a.

\section{Results}

\section{Synoptic conditions}

In the case of Hokkaido, a low-pressure system was located north of Hokkaido and hence westerly wind was dominated over a wide range of Hokkaido (Fig. 2a). Similarly, westerly wind dominated around Tohoku on April 30, 2016, because a developed low-pressure system whose center pressure exceeded more than $976 \mathrm{hPa}$ was located northeast of Hokkaido (Fig. 2b).

In addition, we calculated the Scorer parameter $l^{2}(z)=N^{2}(z) / U^{2}(z)-(1 / U(z))\left(\mathrm{d} U^{2} / \mathrm{d} z^{2}\right)$ using radiosonde observation data, which is an indicator of the mountain-induced gravity wave behavior (Miglietta et al. 2013). Resonant lee waves will develop if $l^{2}$ decrease rapidly with height (Scorer 1949; Doyle and Smith 2003). Operational radiosonde observations suggested that tropospheric conditions were stable in both cases. The existence of the Scorer parameter peak at the height of $8000 \mathrm{~m}$ and the continuous decrease in $l^{2}$ from 2000 to $5000 \mathrm{~m}$ in the case of Tohoku (Fig. 3d) indicated that the synoptic condition was preferable for the wave trapping below this layer (relatively small wave energy linkage to the upper atmosphere). In the case of Hokkaido, the small peak and the subsequent decrease in $l^{2}$ around $2500 \mathrm{~m}$ indicated that condition was preferable to the development of trapped lee waves in the lower troposphere (Fig. 3b).

\section{InSAR observations}

The interferograms detected oscillating phase variations extending to a zonal direction with a wavelength of around $10 \mathrm{~km}$ in both cases (Fig. 4). To validate whether observed signals were due to propagation delay in the troposphere or not, we generated other ScanSAR interferograms acquired at different times. It is noted that ALOS-2 ScanSAR interferometry with SLCs acquired before February 8, 2015, has "the burst overlapping" problem due to the incorrect parameter estimation of the satellite latitude, which causes the misalignment of the radio wave transmission timing (Natsuaki et al. 2016). The successful interferogram generation requires the burst overlapping ratio of at least 50\% (Buckley and Gudipati 2011). In the case of Tohoku, we could use ScanSAR SLC data acquired after February 8, 2015, and thus, we validated that the phase variation in Fig. $4 \mathrm{~b}$ was due to the propagation delay in the troposphere (not shown). On the other hand, in the case of Hokkaido, no other interferograms could be generated due to the burst overlapping problem even though there were several ScanSAR observations in the corresponding area. Therefore,
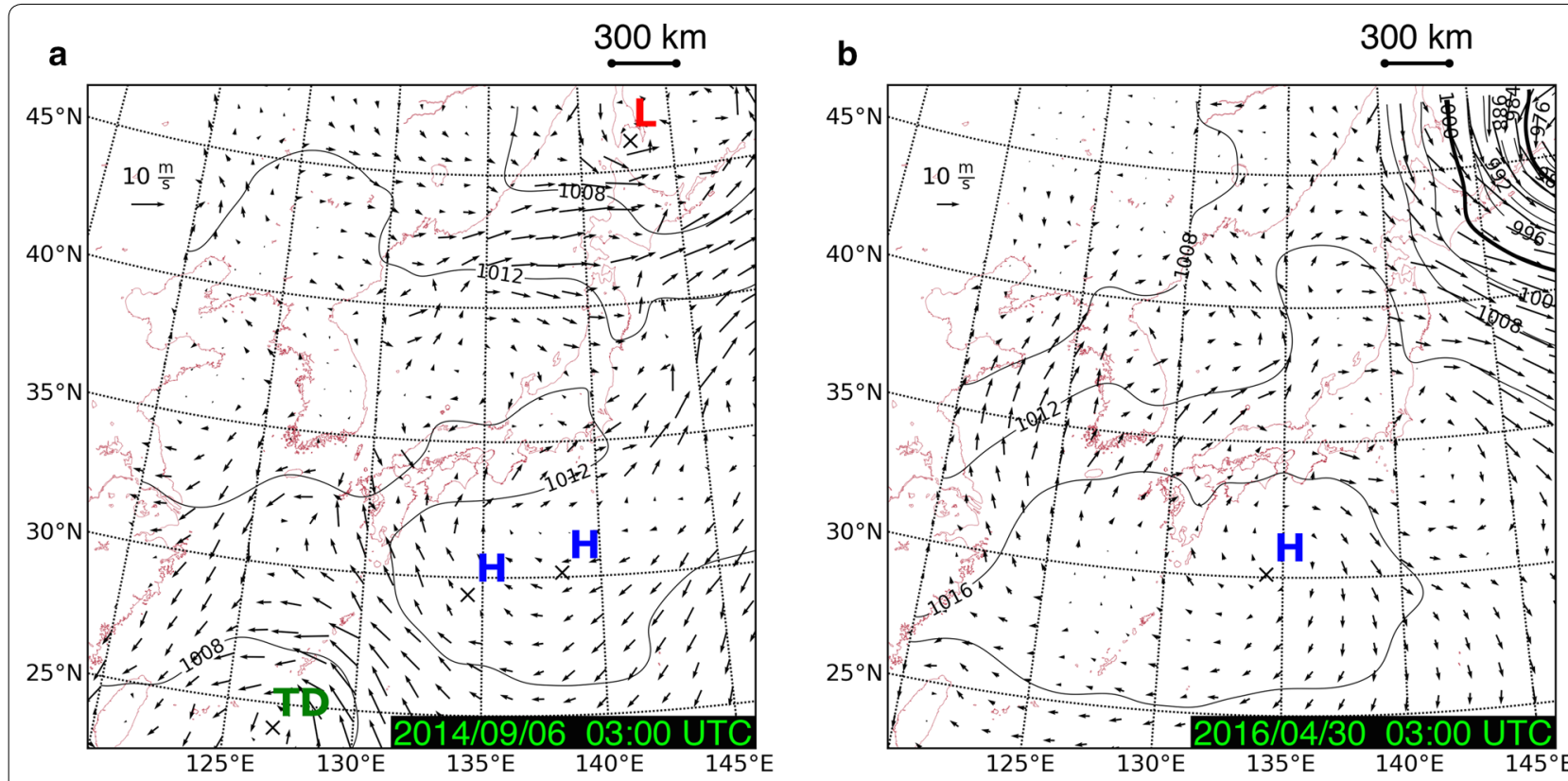

Fig. 2 MSM surface pressure and wind. Sea level pressure (contour, hPa) and surface wind (vector) created from MSM data on the SAR observation days. The times of 03:00 UTC are approximately 30 min later from SAR acquisition times. The symbol " $H$ " indicates the center of a high-pressure system; " $L$ " indicates the center of a low-pressure system; and "TD" indicates a tropical depression 

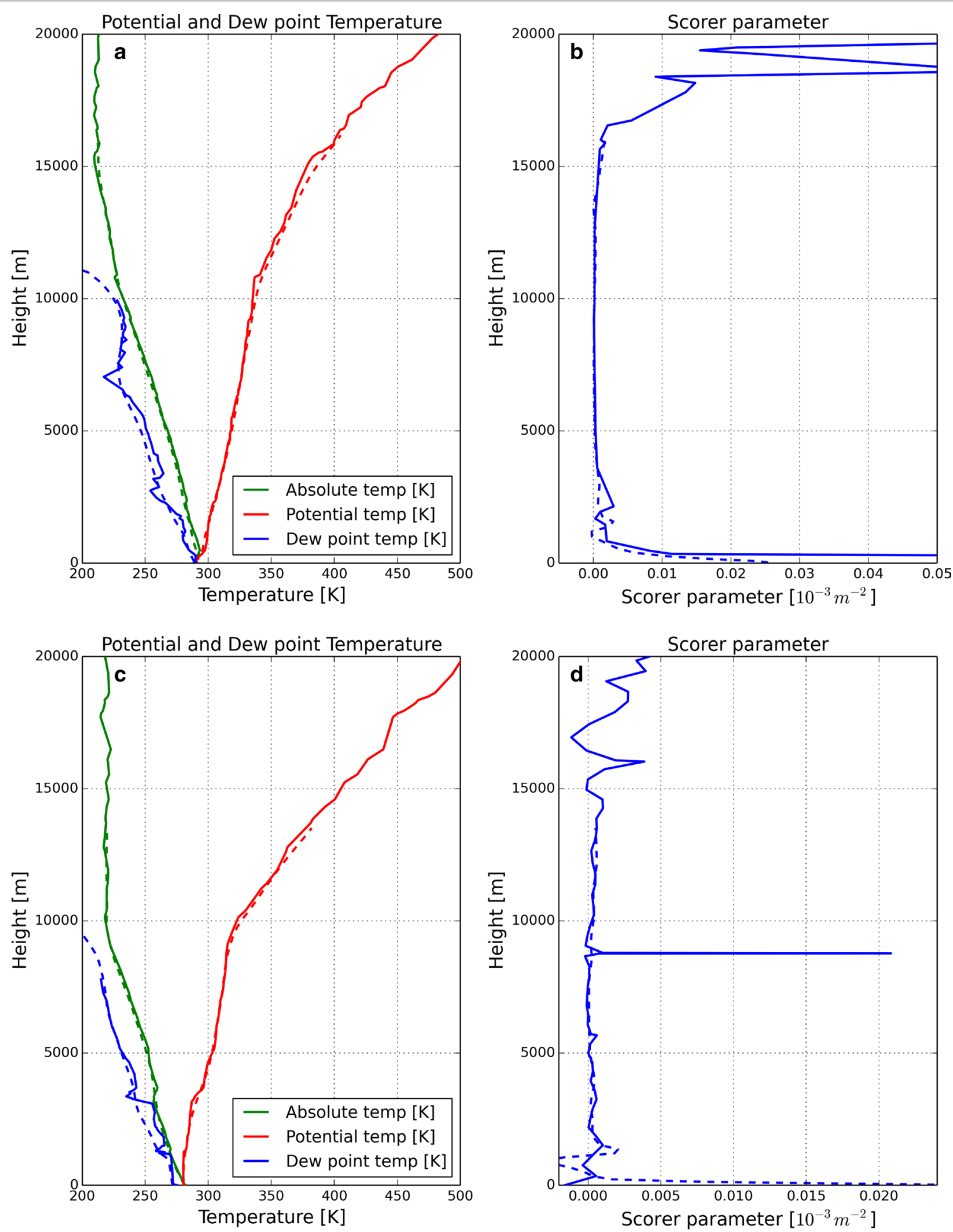

Fig. 3 Radiosonde observed data. Vertical profiles derived by the radiosonde (solid lines) and WRF simulation (dashed lines) at Kushiro station on 00:00 UTC of September 6, 2014, (a, b) and at Akita station on 00:00 UTC of April 30, 2016, (c, d). a, c Green, blue and red lines indicate temperature, dew point temperature and potential temperature, respectively. $\mathbf{b}, \mathbf{d}$ Profiles of the Scorer parameter 

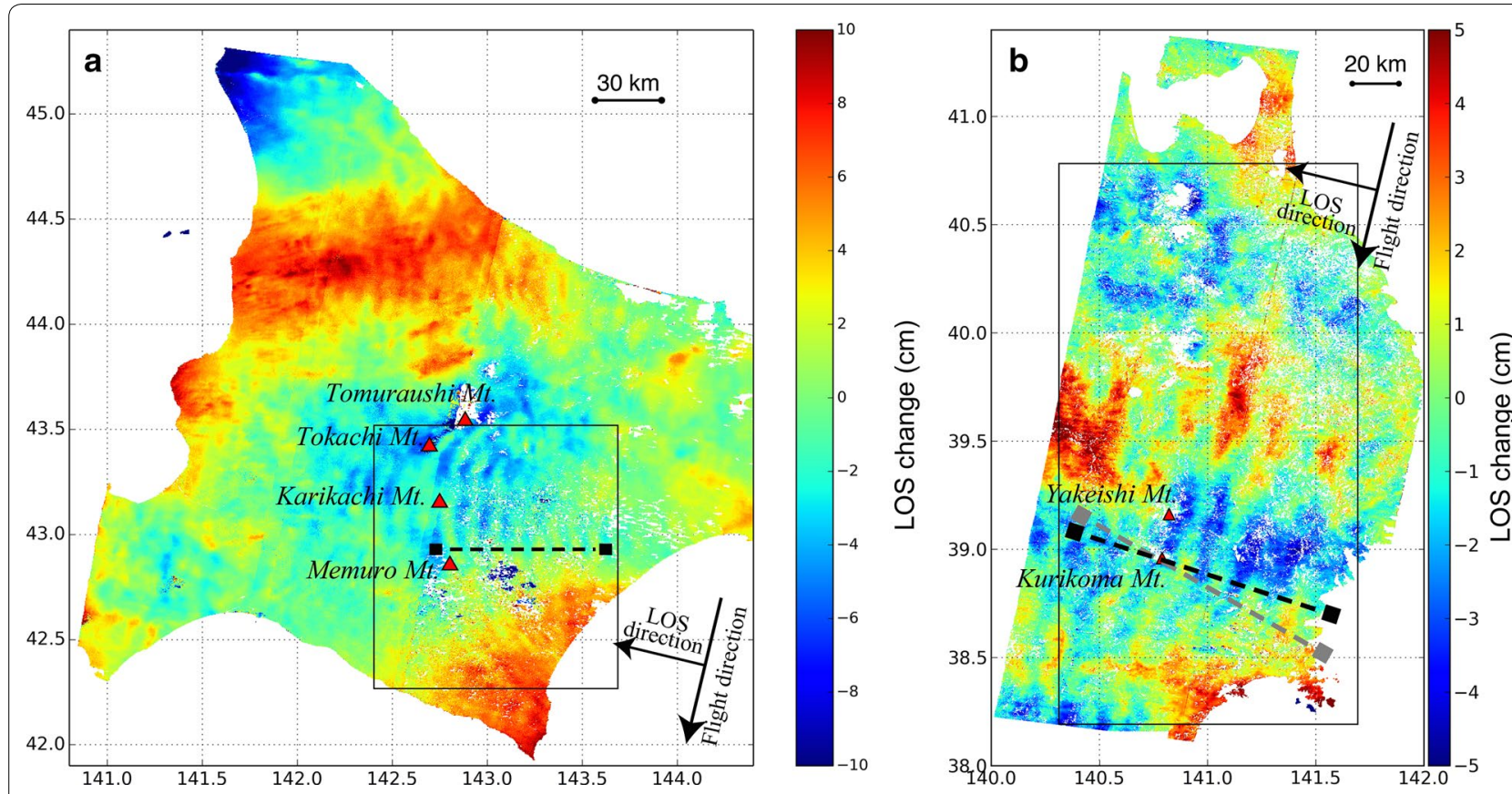

Fig. 4 InSAR images a at Hokkaido on 02:33 UTC of September 6, 2014, and b at Tohoku on 02:34 UTC of April 30, 2016. Red triangles represent locations of the mountain top. Warmer color indicates areas where much water vapor exists relative to the surrounding and cooler color is areas of less water vapor. Black-lined regions indicate areas in Fig. 7. A dashed black line in a indicates the profile in Figs. 6a, 8 and 10. Dashed black and gray lines in b indicate profiles of observed and simulated delays, respectively, in Fig. 9. The dashed black line in $\mathbf{b}$ also indicates the profile in Fig. $6 \mathrm{~b}$

we could not reject possibilities of the detected phase variation caused by surface deformation or ionospheric effect in a rigorous way. However, because operational GNSS observations suggested that no or little deformation have occurred around the Hokkaido area during the ScanSAR observation interval (not shown), and because the interval of acquisition date between the interferometric pair was 42 days, we assumed that there were no surface deformation signals in Fig. 4a. Besides, ionospheric effects in InSAR usually have spatial scale of more than a hundred of kilometers (Kinoshita et al. 2013) and around $20 \mathrm{~km}$ with a patchy shape in cases of sporadic-E events (Maeda et al. 2016). Therefore, we also assumed that the phase variation in Fig. 4a was not due to ionospheric effects.

In the case of Hokkaido, westerly wind blew around the central Hokkaido on 00:00 UTC of September 6, 2014, by MSM data (Fig. 2a) and surface meteorological observations (not shown); phase variations were due to trapped mountain waves initiated on the downslope side of Hidaka Mountains, which propagated to the east direction. The peak-to-trough phase amplitude reached up to $4 \mathrm{~cm}$ in the radar line of sight direction. The corresponding zenith PWV can be approximately estimated by the relation $\mathrm{PWV}_{\mathrm{SAR}}=\Pi \cdot$ Delay $_{\mathrm{SAR}} \cdot \cos \theta$, where $\Pi$ indicates a conversion factor used for GNSS PWV estimation and $\theta$ indicates the incidence angle (Fornaro et al. 2015). Applying this equation, the peak-to-trough phase amplitude corresponds to $5.2 \mathrm{~mm}$ difference in PWV. The InSAR image also showed that the phase variations have 8 crests that have a wavelength of approximately $9 \mathrm{~km}$, far reaching to the east-side boundary of observation. This wavelength was relatively small compared with those reported by previous studies (e.g., Ralph et al. 1997). The satellite visible image derived by the MTSAT-2 at the same time of the SAR acquisition detected only 3 or 4 crests of cloud streets (Fig. 5a), indicating that InSAR could capture an invisible part of the waves. In addition, InSAR also captures mountain wave signals in a cloudy area where multispectrum sensors such as MODIS cannot estimate PWV values.

In the case of Tohoku, oscillating phase variations were detected in the southern part of the InSAR image on 02:34 UTC of April 30, 2016 (Fig. 4b). The phase variations were extending from ENE to WSW that is consistent with wind directions in the MSM data and surface meteorological observation at the same time, and the location of positive phase anomalies in the InSAR image coincided with the location of cloud streets in the satellite visible image by the Himawari-8 (Fig. 5b). Therefore, the phase variations in the case of Tohoku were also due to mountain waves excited by mountains around 

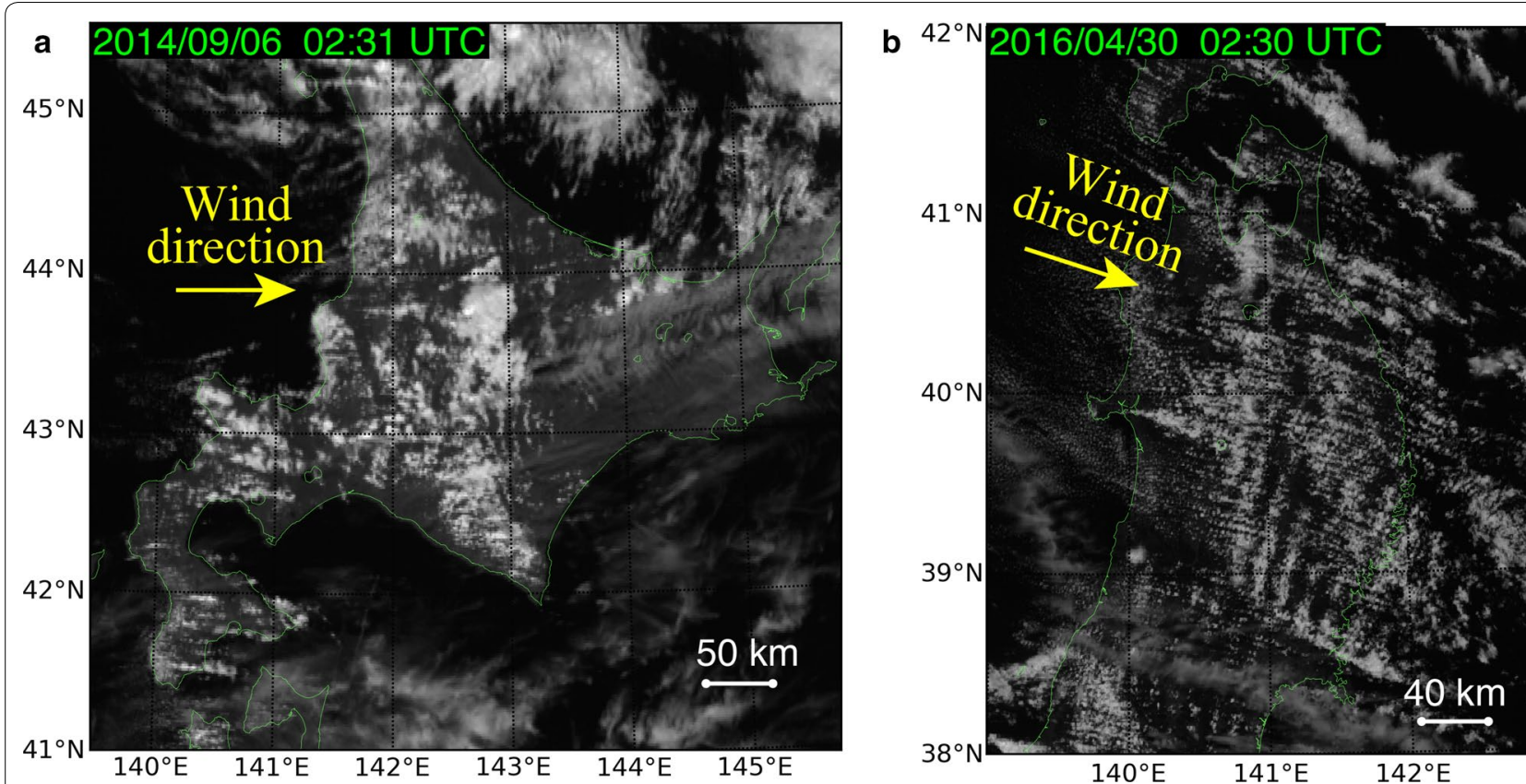

Fig. 5 Visible satellite images derived from a MTSAT-2 on 02:31 UTC of September 6, 2014, and b Himawari-8 on 02:30 UTC of April 30, 2016

the Yakeishi and Kurikoma Mountains, a part of the $\mathrm{Ou}$ Mountains. The mountain wave signals had three or four crests that have a wavelength of $15 \mathrm{~km}$ and the maximum peak-to-trough amplitude of $5 \mathrm{~cm}$.

The InSAR image in the case of Tohoku successfully captured a phase decrease due to strong downslope wind (negative anomaly adjacent to a mountain top) that occurred on lee side of the mountain top. In the downward wind, upper dry air moves toward lower layers, resulting in the decrease in refractivity due to poor water vapor. In the case of Hokkaido, the phase decrease due to the downslope wind was not seen in Fig. 4a. This is because a subsequent upward motion occurred in the middle of the downslope. On the contrary, clear positive anomaly $5 \mathrm{~km}$ to the east of the top of the Karikachi Mountain was observed by InSAR. This positive anomaly obviously had larger amplitude than amplitudes of subsequent trapped waves propagating eastward. This positive anomaly extended from Karikachi Mountain to Memuro Mountain, which locates $28 \mathrm{~km}$ to the south of Karikachi Mountain, suggesting that InSAR was likely to capture the first crest of the mountain wave.

\section{WRF simulations and experiments with different PBL schemes}

WRF simulations with a $1-\mathrm{km}$ horizontal grid spacing successfully reproduced mountain-induced gravity waves in both cases. Wavelengths of mountain waves were 9 and $15 \mathrm{~km}$ in cases of Hokkaido and Tohoku, respectively. Both mountain waves propagated in the directions along wind flows between 3000 and $4000 \mathrm{~m}$ height (Fig. 6).

In the case of Hokkaido, mountain waves were excited by several mountains located in the Hidaka Mountains, for example, the Karikachi Mountain and the Memuro Mountain, and propagated horizontally to the eastern direction (Fig. 7a). The WRF simulation well reproduced a vertical structure of a radiosonde observation at the Kushiro station (dashed lines in Fig. 3a). A vertical cross section of the vertical wind (Fig. 6a) showed that the mountain waves were trapped below approximately $3000 \mathrm{~m}$ and decayed as it propagated. Here, we defined the perturbation refractivity $N^{\prime}=N(x, y, z)-\bar{N}(z)$ as an anomaly from the horizontally averaged refractivity. The cross section of the perturbation refractivity showed that a horizontal heterogeneity of the perturbation refractivity was significant at a height around $1500 \mathrm{~m}$, indicating that vertical motion of mountain waves lifted lower wet air to the upper layer and vice versa. In the upper part of trapped mountain waves, there were little difference of water vapor amount between heights of peaks and troughs, resulting in smaller perturbation refractivity at that height than that in the lower part of trapped waves. In addition, phase of waves in the perturbation refractivity was delayed $\pi / 2$ radian from that in the vertical wind as mentioned by Feltz et al. (2009). 

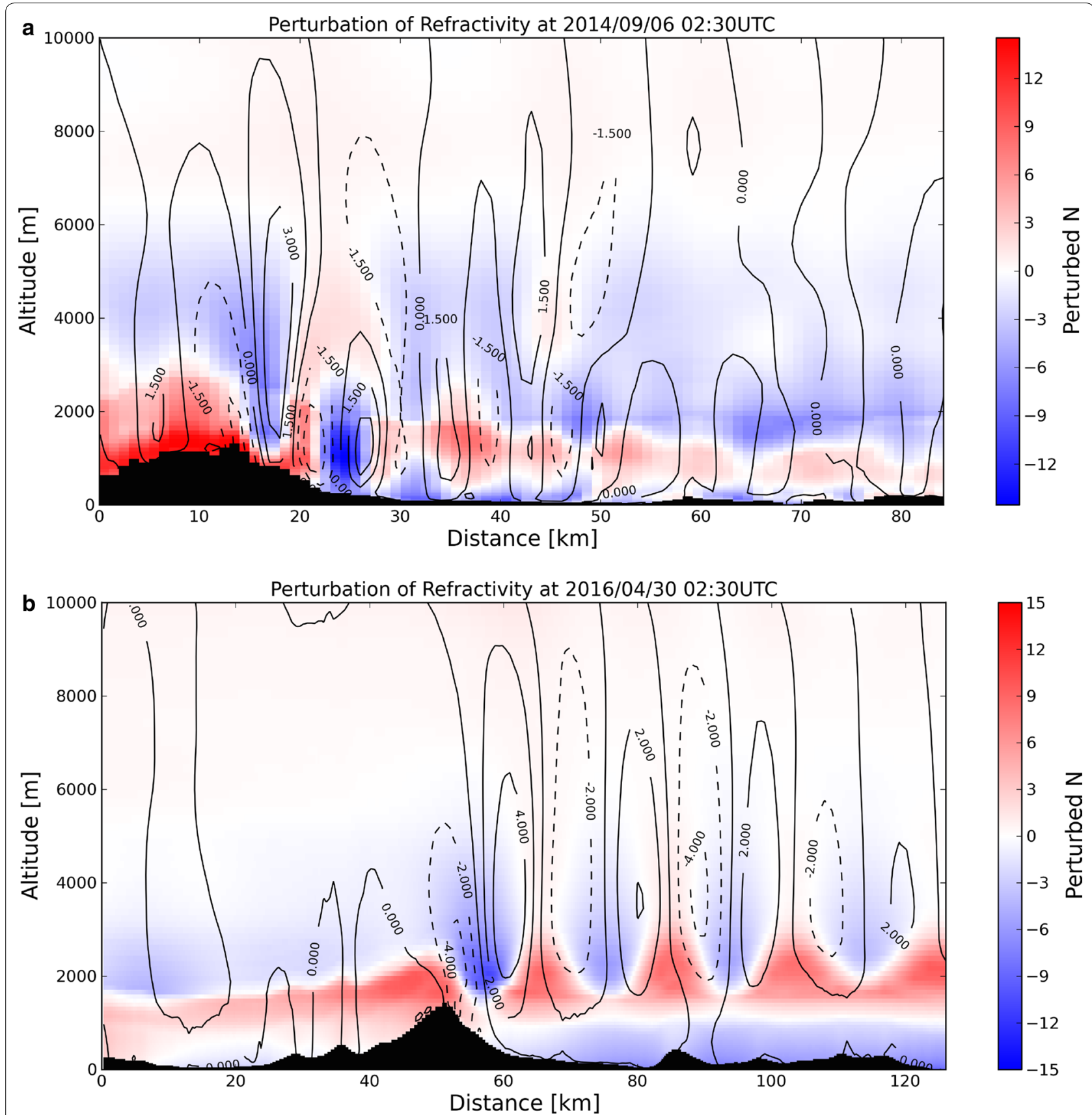

Fig. 6 Vertical profiles of WRF perturbation refractivity. Vertical profiles of perturbation refractivity simulated by WRF along lines shown in Fig. 4. Contour lines represent the vertical wind velocity. a 02:30 UTC on September 6, 2014, and b 02:30 UTC on April 30, 2016

In the case of Tohoku, mountain waves were excited by the Yakeishi Mountain and the Kurikoma Mountain, which propagated to the southeastern direction (Fig. 7b). The modeled wave direction was approximately $11.8^{\circ}$ different from the observed direction shown in the InSAR and satellite visible images. This difference was probably due to the low reproducibility of the WRF initial wind field derived from MSM data. The modeled vertical structure was similar to that derived by the radiosonde observation at the Akita station as well as the case of Hokkaido, except for the absence of sharp peak of the Scorer parameter at the height of $8000 \mathrm{~m}$ in the model (Fig. 3d). The cross section of perturbation refractivity (Fig. 6b) showed that a layer that the spatial heterogeneity 


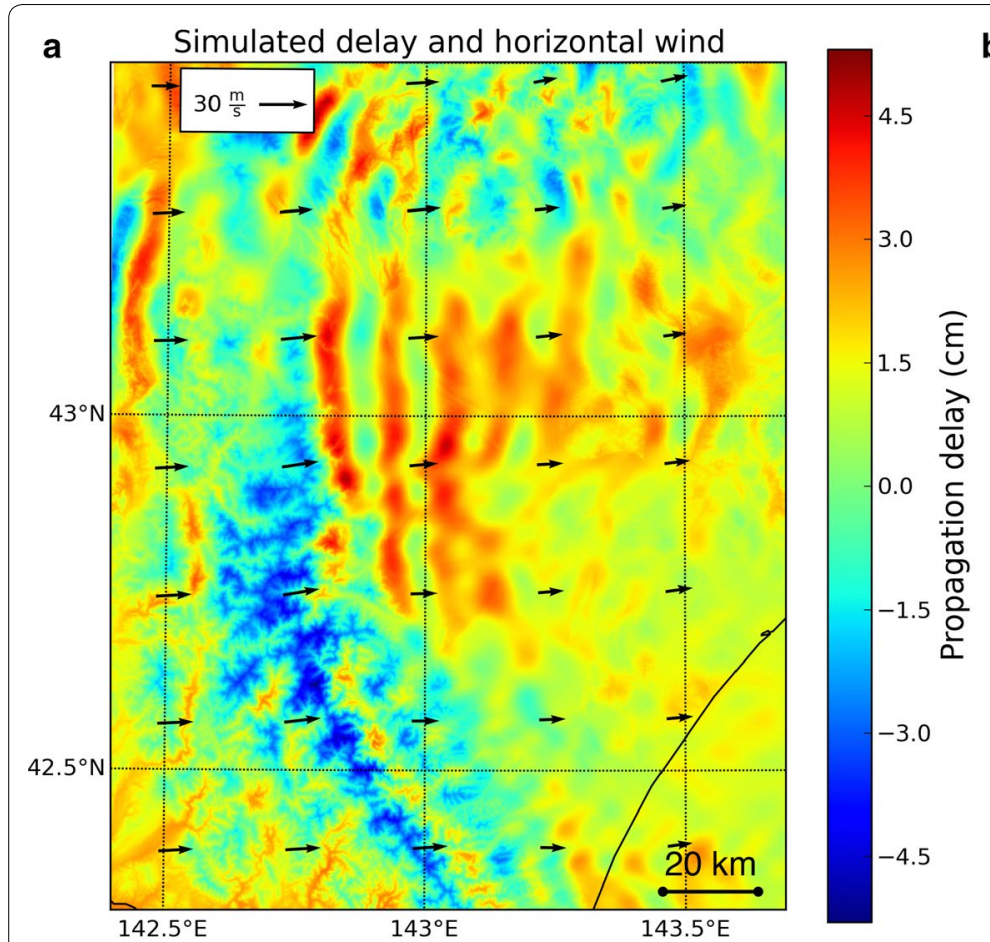

b Simulated delay and horizontal wind

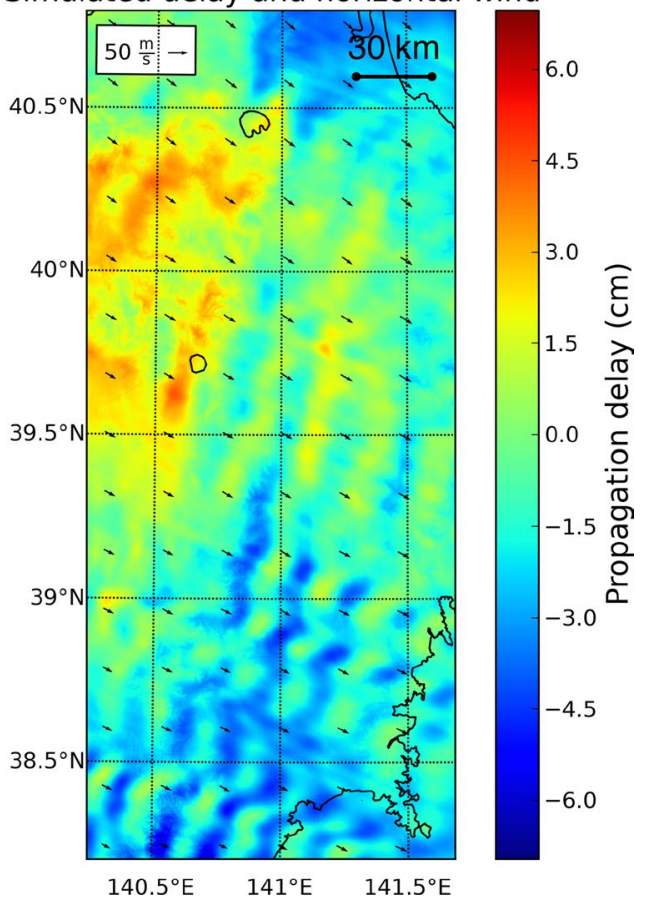

Fig. 7 Simulated propagation delay maps by WRF. Simulated propagation delay maps with horizontal wind vectors at $4000 \mathrm{~m}$ a.s.l. a 02:30 UTC on September 6, 2014, and b 02:30 UTC on April 30, 2016 of perturbation refractivity was significant was located at $2500 \mathrm{~m}$ height.

Results of propagation delay calculation with the ray tracing method showed that in both cases WRF simulations successfully reproduced phase variations due to mountain trapped waves (Fig. 7). In the case of Hokkaido, the simulated propagation delay well captured amplitude and wavelength of the observed phase variation along a profile shown in Fig. 8. The maximum simulated peakto-trough amplitude of the modeled delay reached up to $5 \mathrm{~cm}$ around $20 \mathrm{~km}$ distance in Fig. 8a, which was comparable to the delay amplitude observed by InSAR. The wavelength of observed and simulated delay was approximately $9 \mathrm{~km}$, which was also equivalent to that of the observed wave. On the other hand, the simulated phase variation attenuated more rapidly than that by the observation and dissipated at $50 \mathrm{~km}$ in Fig. 8. In addition, the simulation reproduced an abrupt increase in the phase variation at the downside slope of the mountain, which was detected at the downslope of the Hidaka Mountains in the InSAR image. The modeled spatial delay distribution in the case of Hokkaido is shown in Fig. 7a. The modeled delay captured spatial extent of lee wave signals on the east side of the Hidaka Mountains, although the topography-correlated delay was also significant in the modeled delay. The shape of the modeled delay signal was similar to that of the observed delay signal.

The simulated phase variation in the case of Tohoku also well captured both observed amplitude and wavelength (Figs. 7b, 9). The maximum peak-to-trough amplitude of modeled delay was approximately $5 \mathrm{~cm}$ around $55 \mathrm{~km}$ distance in Fig. 9a. As in the case of Hokkaido, the WRF simulation in the case of Tohoku also reproduced the maximum delay amplitude due to the lee wave observed by InSAR. The wavelength of the phase variation due to the mountain wave at the Kurikoma Mountain was $15 \mathrm{~km}$. The simulated phase variation has three wave crests (from 40 to $90 \mathrm{~km}$ in Fig. 9), and no waves were reproduced east of the $90 \mathrm{~km}$ distance from the mountain top. This rapid attenuation of the modeled trapped wave was similar to that in the simulation result at Hokkaido. This attenuation may arise from the characteristics of the PBL parameterization used in the WRF simulations, which prescribes a mechanism of sub-grid-scale turbulence in the boundary layer. The spatial extent and shape of the modeled delay in the case of Tohoku were also successfully reproduced by the WRF simulation. On the other hand, the horizontal wave direction in terms of water vapor delay was moved $11.8^{\circ}$ in a clockwise direction compared 

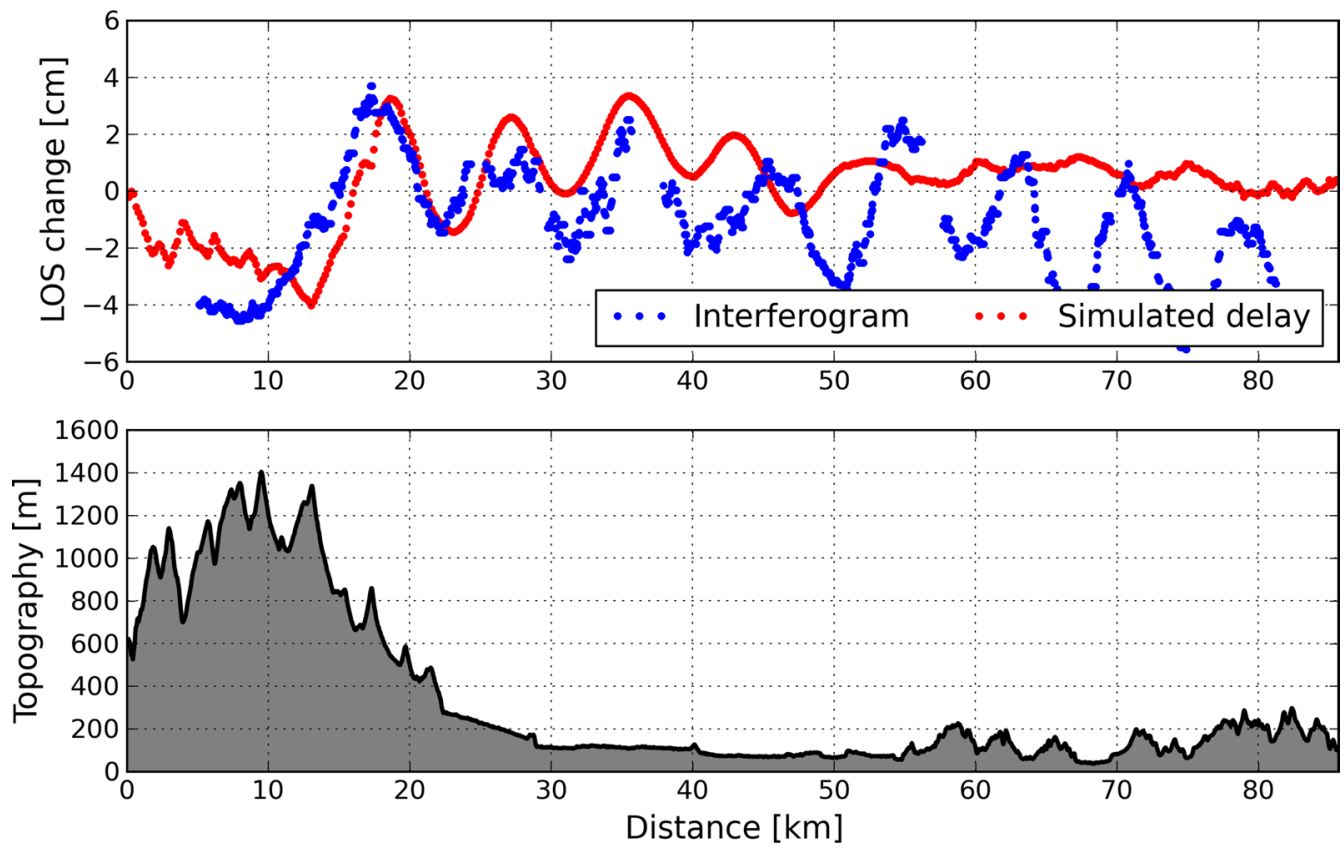

Fig. 8 Phase variation profiles in Hokkaido. (Top) profiles of observed phase variation (blue) and simulated propagation delay (red) along the line shown in Fig. 4a. (Bottom) a profile of topography from GSI 10 m DEM
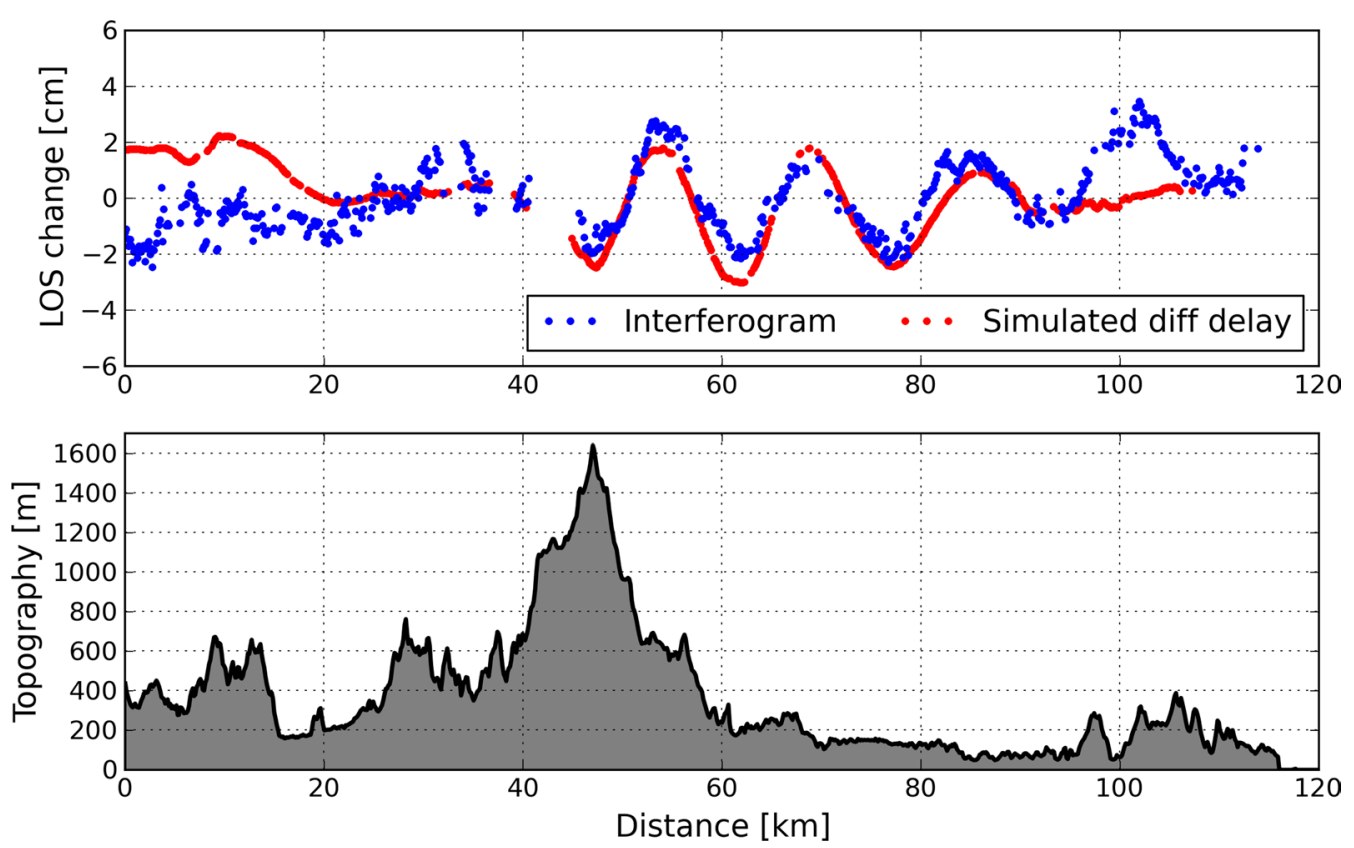

Fig. 9 Phase variation profiles in Tohoku. (Top) profiles of observed phase variation (blue) and simulated propagation delay (red) along gray (InSAR) and black (WRF) lines shown in Fig. 4b. Both lines in Fig. 4b passed through the location of the top of the Kurikoma Mountain. (Bottom) a profile of topography from GSI 10 m DEM

with the observed signal as mentioned before. This is due to the discrepancy of the horizontal wind direction in the lower layer between the modeled and actual atmosphere. Overall, the WRF simulations with the $1-\mathrm{km}$ horizontal grid spacing could reproduce fundamental features of observed lee waves. 
Table 1 List of PBL schemes

\begin{tabular}{|c|c|c|c|c|}
\hline PBL scheme & Abbreviation & Surface layer scheme & Comments & References \\
\hline Yonsei University & YSU & Revised MM5 (Monin-Obukhov-base) & Default setting & Hong et al. (2006) \\
\hline Mellor-Yamada-Janjic & MYJ & Monin-Obukhov for Eta model & & Janjic (1994) \\
\hline Mellor-Yamada-Nakanishi and Niino level 3 & MYNN3 & Revised MM5 (Monin-Obukhov-base) & & Nakanishi and Niino (2006) \\
\hline Asymmetric convective model 2 & ACM2 & (Monin-Obukhov-base) & & Pleim (2007) \\
\hline Quasi-Normal Scale Elimination & QNSE & Quasi-Normal Scale Elimination & & Sukoriansky et al. (2005) \\
\hline
\end{tabular}

To investigate the reason of the rapid wave attenuation in the WRF simulations, we performed other WRF simulations with different PBL schemes in the case of Hokkaido. We compared 5 PBLs including the YSU scheme used before. All PBL schemes used here were incorporated in the WRF model and are shown in Table 1. Other settings of the WRF simulations were the same as the settings of the original simulation described in subsection 2c.

Results (Fig. 10) indicated that only the simulations with the YSU scheme (red dots in Fig. 10) showed a rapid attenuation of the trapped waves, while other simulations showed less attenuation. Wavelengths of the simulated waves slightly differed from each other. The simulation with the Mellow-Yamada-Janjic scheme (MYJ, blue dots in Fig. 10) failed to reproduce a rapid phase increase at the downslope of the mountain and showed complex fluctuation that was not similar to the observation (black

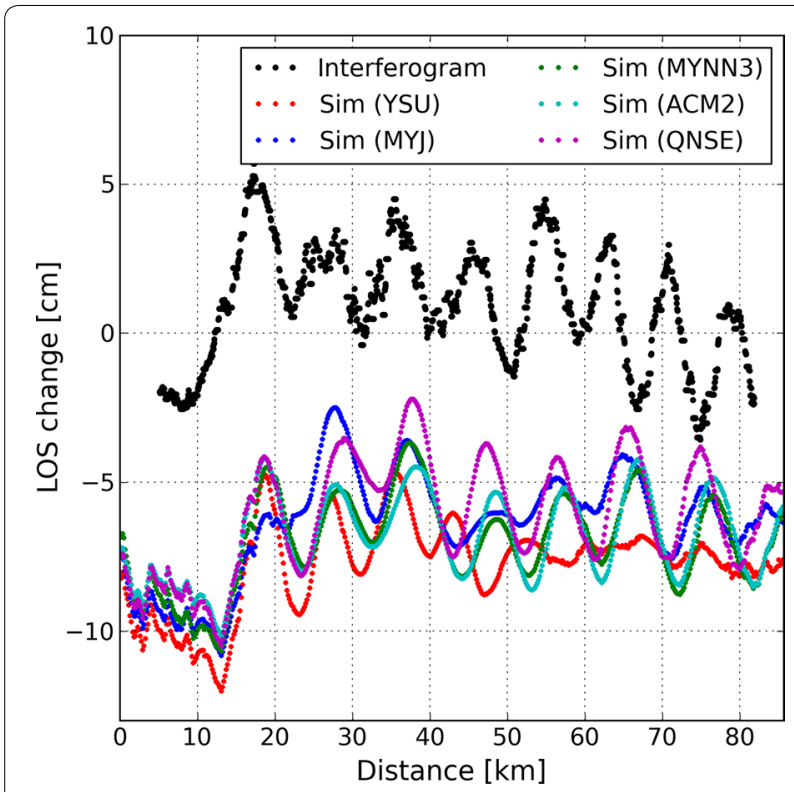

Fig. 10 Phase profiles obtained by different WRF simulations. Profiles same as Fig. 8 with additional profiles derived from four WRF simulations with different PBL schemes. We added offsets in each profile for the purpose of improving the visibility dots in Fig. 10). The simulations with the Mellow-Yamada-Nakanishi and Niino level 3 (MYNN3) and asymmetric convective model 2 (ACM2) schemes (green and cyan dots in Fig. 10) reproduced a rapid phase increase at the downslope and far-reaching wave propagation. However, simulated wavelengths of trapped waves, which were approximately $11 \mathrm{~km}$, were slightly larger than that in the observation. The simulation with the Quasi-Normal Scale Elimination (QNSE) scheme seems to show the best reproducibility of all simulations in terms of the amplitude and attenuation rate, although the wavelength in the YSU scheme was closer to the observation than that in the QNSE scheme. The QNSE simulation (purple dots in Fig. 10) reproduced a rapid phase increase at the downslope and less wave attenuation in the far side, and closer wavelength of approximately $10 \mathrm{~km}$.

\section{Discussion}

Our study demonstrated that a state-of-the-art numerical weather model could well reproduce trapped lee wave signals observed by InSAR. From the view of geodetic researches, this suggests the importance of non-hydrostatic high-spatial-resolution modeling for reducing the atmospheric contribution from InSAR observations. Mitigating effects of atmospheric gravity waves cannot be achieved by the use of global reanalysis data such as the European Centre for Medium-Range Weather Forecasts (ECMWF) ERA40 (Doin et al. 2009) and ERA-Interim (Jolivet et al. 2014; Bekaert et al. 2015). A combination of the non-hydrostatic numerical weather model and the data assimilation method with a variety of meteorological observations like radiosonde, satellite imagery and GNSS-derived PWV would be also helpful for improving the reproducibility of observed mesoscale meteorological phenomena (Kinoshita and Furuya. 2017). The numerical weather model approach for InSAR atmospheric delay correction has the huge potential, and thus, further investigations are needed.

The overestimation of the wave attenuation rate in the YSU scheme shown in the result section would arise from the difference of the PBL type. The YSU scheme is the "non-local" scheme that considers interactions of a layer to multiple levels in representing the effects 
of vertical mixing in the model, while other PBLs is the "local" scheme that only considers immediately adjacent vertical levels in the model or the "hybrid (local and nonlocal)" scheme. As a result, the YSU tends to overdeepen the boundary layer rather than that in other PBLs. This may cause overmixing of turbulent kinetic energy in the layer and result in the rapid attenuation of horizontal lee wave amplitude. To elucidate the limitation of PBL schemes for the mountain lee wave research, it would be better to perform large eddy simulations that explicitly represent three-dimensional turbulence kinetic energy.

InSAR observations revealed detailed spatial water vapor structures of mountain waves. The observation of spatial water vapor distribution itself has been accompanied by the multispectrum satellite observation such as the MODIS satellite as well. Their temporal resolution is basically a few days, which is superior to that of InSAR observations. But they are able to observe only cloud-free areas; thus, they cannot reveal a whole picture of mountain wave with cloud streets, especially around the top of mountains where clouds often appear associated with mountain waves. InSAR can overcome this deficit and can be used as a unique meteorological observation technique to elucidate small-scale spatial structures of mountain waves and other atmospheric phenomena.

The InSAR technique observes water vapor heterogeneity over land because the interferometry requires unchanged scattering characteristics at the surface target. This means that InSAR cannot observe over water body areas like lakes and oceans, which is one of the disadvantages of the InSAR observation. On the contrary, the sea surface wind-retrieval technique by the use of SAR SLC data can retrieve footprints of trapped lee waves that extend toward near the sea surface (e.g., Miglietta et al. 2013). This technique complements unobservable areas of InSAR. Using both InSAR and the SAR windretrieval techniques enables us to capture the wide range of trapped lee waves with no other observations. To our knowledge, there have been no studies that used these two techniques in combination to derive the spatial distribution of trapped lee waves.

\section{Summary}

We detected two cases that included water vapor distributions associated with trapped lee waves in Hokkaido and Tohoku by ALOS-2/PALSAR-2 ScanSAR interferometry. These lee waves occurred under stable atmospheric conditions with westerly and west-northwesterly winds in Hokkaido and Tohoku cases, respectively. Both cases showed that trapped lee waves were extended eastward from mountain tops and had peak-to-trough amplitudes of 4 and $5 \mathrm{~cm}$, and wavelengths of 9 and $15 \mathrm{~km}$ in Hokkaido and Tohoku, respectively. WRF simulations with the horizontal resolution of $1 \mathrm{~km}$ were performed to reproduce InSAR phase variations due to trapped lee waves. Results of WRF simulations showed that observed lee wave signals were successfully reproduced in both cases: peak-to-trough amplitudes and wavelengths of simulated lee waves were approximately same as those of InSARobserved waves although the wave direction in the case of Tohoku was $11.8^{\circ}$ different from the observed direction. This would be due to the discrepancy of the initial wind field in the WRF simulation from the actual situation and hence may be improved by assimilating wind observation data. In addition, simulated lee waves showed that their amplitude decreased as the wave propagated faster than those derived from InSAR observations. To investigate this, other WRF simulations with four different PBL schemes were performed in the case of Hokkaido. The PBL sensitivity test indicated that the attenuation rate (wave energy dissipation) was sensitive to PBL physics, and the wavelength was also sensitive at a certain extent. Among five PBL schemes, the QNSE scheme reproduced the most similar characteristics of trapped lee waves to the observation in terms of amplitude and the attenuation rate. On the other hand, the YSU scheme showed the best reproducibility with regard to the wavelength.

A variety of advantages that L-band InSAR has are unique and thus would be useful for meteorological researchers, especially for the meso-gamma scale (a few kilometer order) or smaller. A previous research by Hanssen et al. (2001) mentioned that, in case of SAR interferometry with higher radar frequency such as X-band and C-band, strong absorption of microwave energy due to severe cloud cover is likely to occur, resulting in missing observation under such a situation. On the other hand, L-band SAR interferometry is little attenuated by cloud hydrometeors (Danklmayer et al. 2009). This cloud-free characteristic is one of the advantages of L-band InSAR among other vertically integrated water vapor observation techniques. One of the applications of InSAR water vapor observation to meteorological research is to assess the PBL scheme reproducibility by comparing the spatial distribution of water vapor or spatial power spectrum of turbulence derived by InSAR with the model results. InSAR may contribute to the improvement of PBL schemes by its unique ability to observe spatial heterogeneity of water vapor with the unprecedented spatial resolution. Although temporal resolution (satellite recurrence period) of satellite-based operational SAR system is one of the biggest disadvantages, for example 46 days in ALOS/PALSAR, 14 days in ALOS-2/PALSAR-2 and 12 days in ESA's Sentinel-1A, recurrence periods have been increasing gradually as a new satellite have been launched, and the combination of multiple SAR satellites improves temporal resolution with a sampling period of a few days or better (Mateus et al. 2013a). If the temporal resolution 
problems are overcome, InSAR could be used for operational meteorological applications such as data assimilation for operational weather forecast simulations.

\begin{abstract}
Abbreviations
3DVAR: three-dimensional data assimilation; ACM2: asymmetric convective model 2; ALOS: the Advanced Land Observing Satellite; ECMWF: the European Centre for Medium-Range Weather Forecasts; ESA: the European Space Agency; GNSS: global navigation satellite system; InSAR: synthetic aperture radar interferometry; JAXA: the Japan Aerospace Exploration Agency; MERIS: the Medium Resolution Imaging Spectrometer; MM5: the revised Pennsylvania State University/National Center for Atmospheric Research mesoscale model; MODIS: the Moderate Resolution Imaging Spectroradiometer; MSM: the MesoScale Model; MYJ: the Mellow-Yamada-Janjic scheme; MYNN3: the Mellow-Yamada-Nakanishi and Niino level 3; NCEP: the National Centers for Environmental Prediction; PALSAR: a Phased Array-type L-band Synthetic Aperture Radar; PBL: planetary boundary layer; PSInSAR: the persistent scatterer interferometry; PWV: precipitable water vapor; QNSE: the Quasi-Normal Scale Elimination; RINC: the Radar Interferometry Calculation Tools; SAR: synthetic aperture radar; SBAS: the Small BAseline Subset interferometry; SLC: single look complex image; SNAPHU: the statistical-cost, network-flow algorithm for phase unwrapping; SST: sea surface temperature; WRF: the Weather and Research Forecasting; YSU: the Yonsei University scheme.
\end{abstract}

\section{Authors' contributions}

YK headed the interferometric analysis, numerical modeling, and examination of the results. He wrote the manuscript. YM conducted interferometric analysis and found a mountain wave signal. YH managed this research. All authors read and approved the final manuscript.

\section{Author details}

1 Research and Development Department, Remote Sensing Technology Center of Japan, 3-17-1, Tokyu REIT Toranomon Building, 3F, Minato-ku, Tokyo, Japan. ${ }^{2}$ Geospatial Information Authority of Japan, Tsukuba, Japan. ${ }^{3}$ Institute of Industrial Science, The University of Tokyo, 4-6-1, Komaba, Meguro-ku, Tokyo, Japan.

\section{Acknowledgements}

The PALSAR-2 level 1.1 data in this study were provided by JAXA through the arrangement of ALOS-2 Fourth Research Announcement (PI:1286). PALSAR-2 data belong to JAXA and the Ministry of Economy, Trade and Industry. The RINC package developed by Dr. T. Ozawa was provided through a working group of the PALSAR Interferometry Consortium to Study our Evolving Land surface (PIXEL). The MSM data were acquired from the grid point value archive site (http://database.rish.kyoto-u.ac.jp/arch/jmadata/) managed by the Research Institute for Sustainable Humanosphere, Kyoto University. MTSAT-2 and Himawari-8 visible image data were provided by the National Institute of Information and Communications Technology (NICT) ScienceCloud data archive site (http://sc-web.nict.go.jp/himawari/himawari-archive.html). We used the Matplotlib Python package for drawing all the figures. We acknowledge two anonymous reviewers for their helpful comments.

\section{Competing interests}

The authors declare that they have no competing interests.

\section{Availability of data and materials}

ALOS-2/PALSAR-2 data can be obtained at the Auig2 archive data search site (https://auig2.jaxa.jp/openam/UI/Login). MSM data can be downloaded from the grid point value archive site (http://database.rish.kyoto-u.ac.jp/ arch/jmadata/) managed by the Research Institute for Sustainable Humanosphere, Kyoto University. MTSAT-2 and Himawari-8 visible image data can be downloaded at the National Institute of Information and Communications Technology (NICT) ScienceCloud data archive site (http://sc-web.nict.go.jp/ himawari/himawari-archive.html). JMA's operational radiosonde data can be downloaded at the JMA homepage.

\section{Consent for publication}

The authors declare that no individual person's data were used in our research.
Ethics approval and consent to participate

The authors declare that no ethics approval and consent to participate is needed for our research.

\section{Funding}

This study is supported by Integrated Research Program for Advancing Climate Models, MEXT, Japan.

\section{Publisher's Note}

Springer Nature remains neutral with regard to jurisdictional claims in published maps and institutional affiliations.

Received: 9 May 2017 Accepted: 31 July 2017

Published online: 15 August 2017

\section{References}

Alshawaf F, Hinz S, Mayer M, Meyer FJ (2014) Constructing accurate maps of atmospheric water vapor by combining interferometric synthetic aperture radar and GNSS observations. J Geophys Res Atmos 120:1391-1403

Bekaert DPS, Walters RJ, Wright TJ, Hooper AJ, Parker DJ (2015) Statistical comparison of InSAR tropospheric correction techniques. Remote Sens Environ 170:40-47

Benevides P, Nico G, Catalão J, Miranda PMA (2016) Bridging InSAR and GPS tomography: a new differential geometrical constraint. IEEE TGRS 54(2):697-702

Berardino P, Fornaro G, Lanari R, Sansosti E (2002) A new algorithm for surface deformation monitoring based on small baseline differential SAR interferograms. IEEE TGRS 40(1 1):2375-2383

Bevis M, Businger S, Herring TA, Rocken C, Anthes RA, Ware RH (1992) GPS meteorology: remote sensing of atmospheric water vapor using the Global Positioning System. J Geophys Res 97(92):787-801

Buckley SM, Gudipati K (2011) Evaluating ScanSAR interferometry deformation time series using bursted stripmap data. IEEE TGRS 49(6):2335-2342

Chang L, Jin S, He X (2014) Assessment of InSAR atmospheric correction using both MODIS near-infrared and infrared water vapor products. IEEE TGRS 52(9):5726-5735

Chen CW, Zebker HA (2002) Phase unwrapping for large SAR interferograms: statistical segmentation and generalized network models. IEEE TGRS 40(8):1709-1719

Danklmayer A, Döring BJ, Schwerdt M, Chandra M (2009) Assessment of atmospheric propagation effects in sar images. IEEE TGRS 47(10):3507-3518

Doin MP, Lasserre C, Peltzer G, Cavalié O, Doubre C (2009) Corrections of stratified tropospheric delays in SAR interferometry: validation with global atmospheric models. J Appl Geophys 69:35-50

Doyle JD, Smith RB (2003) Mountain waves over the Hohe Tauern: influence of upstream diabatic effects. Q J R Meteorol Soc 129:799-823

Durran DR (1990) Mountain waves and downslope winds. Atmos Processes Over Complex Terrain 23(45):59-83

Durran DR, Hills MOG, Blossey PN (2015) The dissipation of trapped lee waves. Part I: leakage of inviscid waves into the stratosphere. J Atmos Sci 72:1569-1584

Feltz WF, Bedka KM, Otkin JA, Greenwald T, Ackerman SA (2009) Understanding satellite-observed mountain-wave signatures using high-resolution numerical model data. Weather Forecast 24:76-86

Ferretti A, Prati C, Rocca F (2000) Nonlinear subsidence rate estimation using permanent scatterers in differential SAR interferometry. IEEE TGRS 38(5):2202-2212

Fornaro G, D'Agostino N, Giuliani R, Noviello C, Reale D, Verde S (2015) Assimilation of GPS-derived atmospheric propagation delay in DInSAR data processing. IEEE JSTARS 8:784-799

Foster J, Brooks B, Cherubini T, Shacat C, Businger S, Werner CL (2006) Mitigating atmospheric noise for InSAR using a high resolution weather model. Geophys Res Lett 33:L16304

Gray AL, Mattar KE, Sofko G (2000) Influence of ionospheric electron density fluctuations on satellite radar interferometry. Geophys Res Lett 27(10):1451-1454 
Hanssen RF, Weckwerth TM, Zebker HA, Klees R (1999) High-resolution water vapor mapping from interferometric radar measurements. Science 283:1297-1299

Hanssen RF, Feijt AJ, Klees R (2001) Comparison of precipitable water vapor observations by spaceborne radar interferometry and meteosat 6.7- $\mu \mathrm{m}$ radiometry. J Atmos Ocean Technol 18:756-764

Hills MOG, Durran DR, Blossey PN (2016) The dissipation of trapped lee waves. Part II: the relative importance of the boundary layer and the stratosphere. J Atmos Sci 73:943-955

Hobiger T, Ichikawa R, Koyama Y, Kondo T (2008) Fast and accurate ray-tracing algorithms for real-time space geodetic applications using numerical weather models. J Geophys Res 113:D20302

Hong SY, Noh Y, Dudhia J (2006) A new vertical diffusion package with explicit treatment of entrainment processes. Mon Weather Rev 134:2318-2341

Janjić ZI (1994) The step-Mountain Eta coordinate model: further developments of the convection, viscous sublayer, and turbulence closure schemes. Mon Weather Rev 122:927-945

Jiang Q, Doyle JD, Smith RB (2006) Interaction between trapped waves and boundary layers. J Atmos Sci 63:617-633

Jolivet R, Grandin R, Lasserre C, Doin MP, Peltzer G (2011) Systematic InSAR tropospheric phase delay corrections from global meteorological reanalysis data. Geophys Res Lett 38:L17311

Jolivet R, Agram PS, Lin NY, Simons M, Doin MP, Peltzer G, Li Z (2014) Improving InSAR geodesy using global atmospheric models. J Geophys Res Solid Earth 119:2324-2341

Kinoshita Y, Furuya M (2017) Localized delay signals detected by synthetic aperture radar interferometry and their simulation by WRF 4DVAR. SOLA 13:79-84

Kinoshita Y, Shimada M, Furuya M (2013) InSAR observation and numerical modeling of the water vapor signal during a heavy rain: a case study of the 2008 Seino event, central Japan. Geophys Res Lett 40:4740-4744

Lane TP, Reeder MJ, Morton BR, Clark TL (2000) Observations and numerical modelling of mountain waves over the Southern Alps of New Zealand. Q J R Meteorol Soc 126:2765-2788

Li Z, Fielding EJ, Cross P, Preusker R (2009) Advanced InSAR atmospheric correction: MERIS/MODIS combination and stacked water vapour models. Int J Remote Sens 30(13):3343-3363

Li ZW, Xu WB, Feng GC, Hu J, Wang CC, Ding XL, Zhu JJ (2012) Correcting atmospheric effects on InSAR with MERIS water vapour data and elevation-dependent interpolation model. Geophys J Int 189(2):898-910

Maeda J, Suzuki T, Furuya M, Heki K (2016) Imaging the midlatitude sporadic E plasma patches with a coordinated observation of spaceborne InSAR and GPS total electron content. Geophys Res, Lett, p 43

Mateus P, Nico G, Catalão J (2013a) Can spaceborne SAR interferometry be used to study the temporal evolution of PWV? Atmos Res 119:70-80

Mateus P, Nico G, Tomé R, Catalão J, Miranda PMA (2013b) Experimental study on the atmospheric delay based on GPS, SAR interferometry and numerical weather model data. IEEE TGRS 51(1):6-11

Mateus P, Tomé R, Nico G, Catalão J (2016) Three-dimensional variational assimilation of InSAR PWV using the WRFDA model. IEEE TGRS 54(12):7323-7330

Mateus P, Catalão J, Nico G (2017) Sentinel-1 interferometric SAR mapping of precipitable water vapor over a country-spanning area. IEEE TGRS 55(5):2993-2999
Meyer FJ (2011) Performance requirements for ionospheric correction of lowfrequency SAR data. IEEE TGRS 49(10):3694-3702

Miglietta MM, Zecchetto S, Biasio FD (2013) A comparison of WRF model simulations with SAR wind data in two case studies of orographic lee waves over the Eastern Mediterranean Sea. Atmos Res 120-121:127-146

Muñoz-Esparza D, Sauer JA, Linn RR (2016) Limitations of one-dimensional mesoscale PBL parameterizations in reproducing mountain-wave flows. J Atmos Sci 73:2603-2614

Nakanishi M, Niino H (2006) An improved Mellow-Yamada level-3 model: its numerical stability and application to a regional prediction of advection fog. Bound Layer Meteorol 119:397-407

Natsuaki R et al (2016) SAR interferometry using ALOS-2 PALSAR-2 data for the Mw 7.8 Gorkha, Nepal earthquake. Earth Planets Space 68:15. doi:10.1186/s40623-016-0394-4

Onn F, Zebker HA (2006) Correction for interferometric synthetic aperture radar atmospheric phase artifacts using time series of zenith wet delay observations from a GPS network. J Geophys Res 111:B09102

Ozawa T, Fujita E, Ueda H (2016) Crustal deformation associated with the 2016 Kumamoto Earthquake and its effect on the magma system of Aso volcano. Earth Planets Space 68:186. doi:10.1186/s40623-016-0563-5

Pichelli E, Ferretti R, Cimini D, Panegrossi G, Perissin D, Pierdicca N, Rocca F, Rommen B (2015) InSAR water vapor data assimilation into mesoscale model MM5: technique and pilot study. IEEE JSTARS 8(8):3859-3875

Pleim JE (2007) A combined local and nonlocal closure model for the atmospheric boundary layer, part I: model description and testing. J Appl Meteorol Climatol 46:1383-1395

Ralph FM, Neiman PJ, Keller TL, Levinson D, Fedor L (1997) Observations, simulations, and analysis of nonstationary trapped lee waves. J Atmos Sci 54:1308-1333

Rosen PA, Hensley S, Joughin IR, Li FK, Madsen SN, Rodríguez E, Goldstein RM (2000) Synthetic aperture radar interferometry. IEEE 88(3):333-382

Scorer RS (1949) Theory of waves in the lee of mountains. Q J R Meteorol Soc 75:41-56

Skamarock WC et al (2008) A description of the advanced research WRF version 3, NCAR technical note. NCAR/TN-475 + STR

Sukoriansky S, Galperin B, Perov V (2005) Application of a new spectral theory of stably stratified turbulence to the atmospheric boundary layer over sea ice. Bound Layer Meteorol 117:231-257

Thayer GD (1974) An improved equation for the radio refractive index of air. Radio Sci 9(10):803-807

Uhlenbrock NL, Bedka KM, Feltz WF, Ackerman SA (2007) Mountain wave signatures in MODIS 6.7- $\mu \mathrm{m}$ imagery and their relation to pilot reports of turbulence. Weather Forecast 22:662-670

Worthington RM (2001) Alignment of mountain lee waves viewed using NOAA AVHRR imagery, MST radar, and SAR. Int J Remote Sens 22(7):1361-1374

Zebker HA, Rosen P, Hensley S (1997) Atmospheric effects in interferometric synthetic aperture radar surface deformation and topographic maps.J Geophys Res 102(B4):7547-7563

\section{Submit your manuscript to a SpringerOpen ${ }^{\odot}$ journal and benefit from:}

- Convenient online submission

- Rigorous peer review

- Open access: articles freely available online

- High visibility within the field

- Retaining the copyright to your article

Submit your next manuscript at $\boldsymbol{\nabla}$ springeropen.com 